\title{
Implementasi Sistem Penunjang Keputusan Dalam Pemilihan Calon Team Leader Menggunakan Metode Simple Additive Weighting (SAW)
}

\author{
Ade Rizki Sariaman Purba ${ }^{1}$, Dewi Kusumaningsih ${ }^{2}$ \\ ${ }^{1}$ Program Studi Teknik Informatika, Universitas Budi Luhur, Jl. Ciledug Raya, RT.10/RW.2, \\ Petukangan Utara, Kec. Pesanggrahan, Kota Jakarta Selatan, Daerah Khusus Ibukota Jakarta, Indonesia, \\ 12260 \\ e-mail: ${ }^{1} 1611510247 @$ student.budiluhur.ac.id, ${ }^{2}$ dewi.kusumaningsih@budiluhur.ac.id
}

Submitted Date: December 23 $3^{\text {rd }}, 2020$

Revised Date: December 31 ${ }^{\text {st }}, 2020$
Reviewed Date: December 31 $31^{\text {st }}, 2020$

Accepted Date: January $05^{\text {th }}, 2021$

\begin{abstract}
So far, the selection of prospective Team Leaders in companies is still manual so it is not in accordance with the standard operating procedures for selection. The system designed in this study aims to ensure the accuracy of HRD in selecting candidates Team Leader to match the expectations of the company itself. From the comparison of the methods that have been carried out by researchers, themethod is the Simple Additive Weighting (SAW)right choice and the researcher will implement it with the provisions of the criteria that have been set including, Communication, Problem Solving Skills, Time Management, English, Achievement. To build this system, researchers used the programming languages PHP and MySQL. From the calculation of the level of accuracy, manual calculations get a percentage of $86.6 \%$ while the calculation with the proposed system achieves the maximum result with a percentage of $100 \%$. It can be concluded that the calculation with the system is able to determine a suitable candidate as a Team Leader very accurately and on target.
\end{abstract}

Keywords: Decision Support System; Simple Additive Weighting (SAW); Selection of Candidates for Team Leaders; Waterfall

\begin{abstract}
Abstrak
Pemilihan calon Team Leader pada perusahaan selama ini masih manual sehingga kurang sesuai dengan standar operasional prosedur pemilihannya. Sistem yang di rancang dalam penelitian ini bertujuan umtuk memastikan tingkat keakurasian HRD dalam memilih Calon Team Leader agar sesuai dengan harapan perusahaan itu sendiri. Dari perbandingan metode yang sudah dilakukan peneliti, metode Simple Additive Weighting (SAW) menjadi pilihan yg tepat dan akan diimplementasikan peneliti dengan ketentuan kriteria yang telah ditetapkan diantaranya, Komunikasi, Problem Solving Skill, Time Management, Bahasa Inggris, Achievement. Untuk membangun sistem ini peneliti menggunakan bahasa pemrograman PHP dan MySQL. Dari hasil perhitungan tingkat akurasi, perhitungan manual mendapatkan persentase $86,6 \%$ sedangkan perhitungan dengan sistem usulan mencapai hasil maximal dengan persentase $100 \%$. Dapat disimpulkan perhitungan dengan sistem mampu menentukan kandidat yang layak sebagai Team Leader dengan sangat akurat dan tepat sasaran.
\end{abstract}

Kata kunci: Simple Additive Weighting (SAW); Sistem Penunjang Keputusan; Pemilihan Calon Team Leader; Waterfall

\section{Pendahuluan}

Pemilihan calon Team Leader yang dilakukan oleh perusahaan menarik rasa keinginan kandidat untuk berlomba-lomba menjadi yang terbaik, namun kadang kala yang menjadi kesulitan ketika HRD memberikan sistem penilaian dengan ketidakjelasan indikator yang digunakan sehingga terpilihnya kandidat yang kurang tepat untuk perusahaan (Simatupang, 2018).

Selama ini pemilihan Team leader pada perusahaan dilakukan dengan sistem manual sehingga hasil penilaian dari HRD kurang akurat 
dan tidak fair. Pada penelitian kali ini peneliti ingin membangun suatu sistem yaitu Sistem Penunjang Keputusan (SPK) sistem ini didukung oleh banyak alternatif yg secara interaktif dipakai oleh user bertujuan untuk mempermudah Pihak HRD dalam menentukan kandidat yang sesuai dengan kebutuhan perusahaan itu sendiri. (Gaol \& Hasibuan, 2018) (Marpaung, 2018).

Proses Pengambilan keputusan dalam menggunakan dukungan komputer berada didalam sistem SPK itu sendiri. SPK juga dapat berperan menjadi dukungan manajer dalam meyelesaikan suatu permasalahan. Dengan adanya penerapan Sistem Penunjang Keputusan (SPK) dapat membantu HRD dalam menentukan kandidat terbaik, ada banyak metode yang dapat di tuangkan ke dalam SPK itu sendiri. (Nurrahmi \& Misbahuddin, 2019).

SPK yang menerapkan Simple Additive Weighting (SAW) dapat membantu dalam pembuatan keputusan (Taufiq \& Mustofa, 2017). Metode $S A W$ dinilai sebagai metode yang tepat dalam pemilihan calon Team Leader dikenal dengan istilah metode penjumlahan terbobot. Konsep dasar metode $S A W$ adalah mencari penjumlahan terbobot dari setiap alternatif pada semua atribut. Hal yang dimaksud adalah alternatif yang layak menjadi Team Leader berdasarkan kriteria yang sudah ditetapkan diantaranya Komunikasi, Problem Solving Skill, Time Management, Bahasa Inggris dan Achievement (Putra et al., 2018) (Agustina, 2019).

Tujuan dari penelitian ini adalah untuk memudahkan HRD dalam memilih Team Leader pada perusahaan, keefektifan metode Simple Additive Weighting (SAW) dapat menanggulangi permasalahan yang kompleks, dengan dibangunnya Sistem Pendukung Keputusan (SPK) dalam pemilihan calon Team Leader diharapkan bisa menemukan kandidat yang tepat dan benar (Resti, 2017).

\section{Metodologi Penelitian}

Sistem Penunjang Keputusan yang dirancang oleh peneliti akan menggunakan model pengembangan waterfall (air terjun). Beberapa tahapan yang akan diterapkan adalah sebagai berikut:

1. Analisis Kebutuhan Sistem

Pada tahap analisis kebutuhan sistem peneliti mengeksplorasi keperluan dan ketentuan yang berhubungan dengan masukan, proses dan keluaran. Seperti apa alternatif yang dibutuhkan HRD dalam memilih kandidat dan keluaran apa yang dapat membantu HRD dalam menentukan keputusan.

2. Desain

Dalam tahapan proses perancangan/desain mencakup susunan klasifikasi program untuk melancarkan pengguna pada saat menjalankan program dan perancangan antar muka. Hal ini di butuhkan untuk kebutuhan sistem dalam berinteraksi dengan penngguna.

3. Coding

Pada tahapan coding (pengkodean) tersimpul bahasa program yang dapat diartikan komputer ketika user (programmer) menerapkannya. Proses penyusunan modul program dilakukan sesuai dengan klasifikasi pada tahap perancangan/desain.

4. Testing

Sistem pengujian merangkum data pilihan sebagai masukan (input) pada Sistem Penunjang Keputusan sehingga membangun nilai akhir sebagai evaluasi untuk menentukan keputusan (Cahyono \& Hadikurniawati, 2019).

\section{Hasil dan Pembahasan}

\section{A. Implementasi Metode SAW}

Tahap-tahap untuk mendefinisikan rancangan pemilihan kandidat sebagai Team Leader dalam memanfaatkan metode Simple Additive Weighting (SAW) adalah sebagai berikut:

1. Menentukan Kriteria

Mendefinisikan kelima kriteria yang akan menjadi dukungan sebagai referensi dalam pemilihan kandidat sebagai Team Leader, kelima kriteria itu adalah Komunikasi, Problem Solving Skill, Time Management, Bahasa Inggris, dan Achievement. Kemudian untuk perhitungan persentase disetiap karakter nya sudah ditentukan oleh pihak perusahaan yang akan menjadi penilaian HRD terhadap kandidat (alternatif) (Kurniawan \& Santika, 2020). 
Tabel 1. Kriteria Kandidat Team Leader

\begin{tabular}{|c|c|l|c|}
\hline $\begin{array}{c}\text { Kode } \\
\text { Kriteria }\end{array}$ & $\begin{array}{c}\text { Jenis } \\
\text { Kriteria }\end{array}$ & Keterangan & Bobot \\
\hline C1 & Benefit & Komunikasi & 20 \\
\hline C2 & Benefit & $\begin{array}{l}\text { Problem } \\
\text { Solving Skill }\end{array}$ & 20 \\
\hline C3 & Benefit & $\begin{array}{l}\text { Time } \\
\text { Management }\end{array}$ & 20 \\
\hline C4 & Benefit & Bahasa Inggris & 20 \\
\hline C5 & Benefit & Achievement & 20 \\
\hline
\end{tabular}

2. Alternatif Kandidat Team Leader

Pada tabel ini menjelaskan data di setiap alternatif yang sudah ditentukan Tabel 2. Alternatif Kandidat Team Leader

\begin{tabular}{|c|l|}
\hline $\begin{array}{c}\text { Kode } \\
\text { Alternatif }\end{array}$ & \multicolumn{1}{c|}{ Keterangan } \\
\hline $\mathrm{A}_{1}$ & Ade Rizki Sariaman Purba \\
\hline $\mathrm{A}_{2}$ & Aldy Istna Putra \\
\hline $\mathrm{A}_{3}$ & Nurovik \\
\hline $\mathrm{A}_{4}$ & Muhammad Ainurrahman \\
\hline $\mathrm{A}_{5}$ & Faisal Arief Deswar \\
\hline $\mathrm{A}_{6}$ & Rizal Riadusurur \\
\hline $\mathrm{A}_{7}$ & Rizki \\
\hline $\mathrm{A}_{8}$ & Sandi Oktarian \\
\hline $\mathrm{A}_{9}$ & Adi Syahputra \\
\hline $\mathrm{A}_{10}$ & Andi Rustianto \\
\hline $\mathrm{A}_{11}$ & Muhammad Jamaludin \\
\hline $\mathrm{A}_{12}$ & Martin Hasiholan \\
\hline $\mathrm{A}_{13}$ & Erwin Sudito Sihombing \\
\hline $\mathrm{A}_{14}$ & Agus Hardiansyah \\
\hline $\mathrm{A}_{15}$ & Lukman Syardi \\
\hline & \\
\hline
\end{tabular}

3. Divisi penilaian

Pada tabel ini menjelaskan bahwa di setiap nilai terdapat divisi nya masingmasing, diantaranya:

Tabel 3. Divisi Penilaian

\begin{tabular}{|c|c|}
\hline Divisi & Nilai \\
\hline Terbaik & 10 \\
\hline Baik & 8 \\
\hline Cukup & 6 \\
\hline Buruk & 4 \\
\hline Terburuk & 2 \\
\hline
\end{tabular}

4. Menentukan nilai alternatif

Berikut masukan nilai keseluruhan kriteria pada setiap alternatif yang sudah ditentukan oleh perusahaan atau HRD.

Tabel 4. Nilai Alternatif di setiap Kriteria

\begin{tabular}{|c|c|c|c|c|c|}
\hline Alternatif & $\mathbf{C}_{\boldsymbol{1}}$ & $\mathbf{C}_{\boldsymbol{2}}$ & $\mathbf{C}_{\boldsymbol{3}}$ & $\mathbf{C}_{\boldsymbol{4}}$ & $\mathbf{C}_{\boldsymbol{5}}$ \\
\hline $\mathrm{A}_{\boldsymbol{1}}$ & 6 & 4 & 2 & 6 & 2 \\
\hline $\mathrm{A}_{2}$ & 2 & 6 & 2 & 4 & 4 \\
\hline
\end{tabular}

\begin{tabular}{|c|c|c|c|c|c|}
\hline Alternatif & $\mathbf{C}_{\mathbf{1}}$ & $\mathbf{C}_{\mathbf{2}}$ & $\mathbf{C}_{\mathbf{3}}$ & $\mathbf{C}_{\mathbf{4}}$ & $\mathbf{C}_{\boldsymbol{5}}$ \\
\hline $\mathrm{A}_{3}$ & 4 & 2 & 2 & 6 & 2 \\
\hline $\mathrm{A}_{4}$ & 4 & 2 & 2 & 2 & 2 \\
\hline $\mathrm{A}_{5}$ & 6 & 2 & 4 & 8 & 6 \\
\hline $\mathrm{A}_{6}$ & 8 & 4 & 2 & 2 & 8 \\
\hline $\mathrm{A}_{7}$ & 10 & 2 & 6 & 8 & 4 \\
\hline $\mathrm{A}_{8}$ & 6 & 8 & 2 & 2 & 8 \\
\hline $\mathrm{A}_{9}$ & 8 & 2 & 4 & 2 & 2 \\
\hline $\mathrm{A}_{10}$ & 10 & 4 & 6 & 8 & 6 \\
\hline $\mathrm{A}_{11}$ & 10 & 8 & 10 & 6 & 4 \\
\hline $\mathrm{A}_{12}$ & 10 & 2 & 8 & 8 & 6 \\
\hline $\mathrm{A}_{13}$ & 2 & 4 & 4 & 6 & 6 \\
\hline $\mathrm{A}_{14}$ & 4 & 8 & 6 & 8 & 8 \\
\hline $\mathrm{A}_{15}$ & 4 & 2 & 2 & 2 & 8 \\
\hline
\end{tabular}

5. Normalisasi

Pada perhitungan normalisasi jika kriteria bersifat benefit dibagi dengan nilai maximum, jika kriteria bersifat cost dibagi dengan nilai minimum. Seperti pada $A_{1}$ yang nilai $C_{1}$ nya 6 dibagi dengan nilai maximum pada baris $C_{1}$ yaitu 10 sehingga $6 / 10=0,6$ sebaliknya dengan cost dibagi dengan nilai minimum.

Tabel 5. Hasil Normalisasi

\begin{tabular}{|c|c|c|c|c|c|}
\hline Alternatif & $\mathbf{C}_{\mathbf{1}}$ & $\mathbf{C}_{\mathbf{2}}$ & $\mathbf{C}_{\mathbf{3}}$ & $\mathbf{C}_{\mathbf{4}}$ & $\mathbf{C}_{\mathbf{5}}$ \\
\hline $\mathrm{A}_{\mathbf{1}}$ & 0,6 & 0,5 & 0,2 & 0,75 & 0,25 \\
\hline $\mathrm{A}_{2}$ & 0,2 & 0,75 & 0,2 & 0,5 & 0,5 \\
\hline $\mathrm{A}_{3}$ & 0,4 & 0,25 & 0,2 & 0,75 & 0,25 \\
\hline $\mathrm{A}_{4}$ & 0,4 & 0,25 & 0,2 & 0,25 & 0,25 \\
\hline $\mathrm{A}_{5}$ & 0,6 & 0,25 & 0,4 & 1 & 0,75 \\
\hline $\mathrm{A}_{6}$ & 0,8 & 0,5 & 0,2 & 0,25 & 1 \\
\hline $\mathrm{A}_{7}$ & 1 & 0,25 & 0,6 & 1 & 0,5 \\
\hline $\mathrm{A}_{8}$ & 0,6 & 1 & 0,2 & 0,25 & 1 \\
\hline $\mathrm{A}_{9}$ & 0,8 & 0,25 & 0,4 & 0,25 & 0,25 \\
\hline $\mathrm{A}_{!}$ & 1 & 0,5 & 0,6 & 1 & 0,75 \\
\hline $\mathrm{A}_{11}$ & 1 & 1 & 1 & 0,75 & 0,5 \\
\hline $\mathrm{A}_{12}$ & 1 & 0,25 & 0,8 & 1 & 0,75 \\
\hline $\mathrm{A}_{13}$ & 0,2 & 0,5 & 0,4 & 0,75 & 0,75 \\
\hline $\mathrm{A}_{14}$ & 0,4 & 1 & 0,6 & 1 & 1 \\
\hline $\mathrm{A}_{15}$ & 0,4 & 0,25 & 0,2 & 0,25 & 1 \\
\hline
\end{tabular}

6. Ranking

Hasil akhir didapatkan dari perkalian matriks ternormalisasi dengan masing-masing bobot kriteria sehingga mendapatkan nilai dan ranking pada setiap alternatif.

Contoh pada $\mathrm{A}_{1}:(0,6 * 20)+(0,5 * 20)+$ $(0,2 * 20)+(0,75 * 20)+(0,25 * 20)=46$ 
Tabel 6. Hasil Ranking

\begin{tabular}{|c|c|c|}
\hline Alternatif & Jumlah & Ranking \\
\hline $\mathrm{A}_{11}$ & 85 & 1 \\
\hline $\mathrm{A}_{14}$ & 80 & 2 \\
\hline $\mathrm{A}_{10}$ & 77 & 3 \\
\hline $\mathrm{A}_{12}$ & 76 & 4 \\
\hline $\mathrm{A}_{7}$ & 67 & 5 \\
\hline $\mathrm{A}_{8}$ & 61 & 6 \\
\hline $\mathrm{A}_{5}$ & 60 & 7 \\
\hline $\mathrm{A}_{6}$ & 55 & 8 \\
\hline $\mathrm{A}_{13}$ & 52 & 9 \\
\hline $\mathrm{A}_{1}$ & 46 & 10 \\
\hline $\mathrm{A}_{2}$ & 43 & 11 \\
\hline $\mathrm{A}_{15}$ & 42 & 12 \\
\hline $\mathrm{A}_{9}$ & 39 & 13 \\
\hline $\mathrm{A}_{3}$ & 37 & 14 \\
\hline $\mathrm{A}_{4}$ & 27 & 15 \\
\hline
\end{tabular}

Berdasarkan tabel di atas dapat disimpulkan yang terpilih sebagai alternatif terbaik adalah $\mathrm{A}_{11}$ (Muhammad Jamaludin) dengan perolehan nilai 85 .

\section{B. Use Case Diagram}

Use Case Diagram menjelaskan relasi antara HRD dengan sistem.

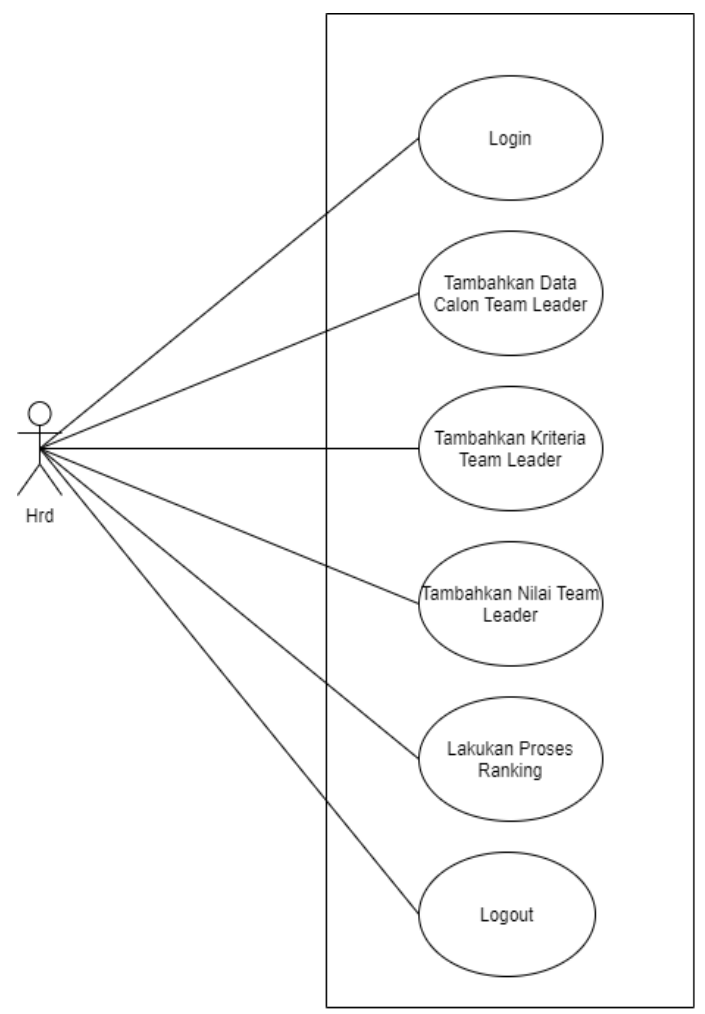

Gambar 1. Use Case Diagram

\section{Tampilan Layar}

Pada tampilan layar peneliti menjelaskan tetang tampilan output program yang sudah dirancang dari proses input data alternatif sampai pada hasil pemeringkatan. Di antaranya:

1. Tampilan Menu Login

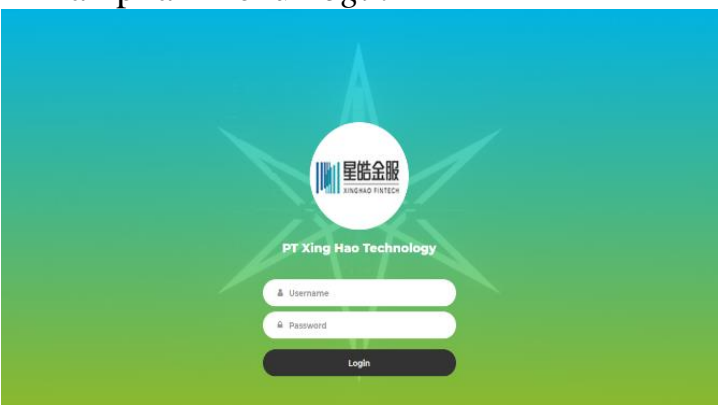

Gambar 2. Tampilan Menu Login

Untuk masuk ke dalam sistem HRD melakukan login terlebih dahulu dengan username dan password yang sudah ditentukan.

\section{Tampilan Menu Home}

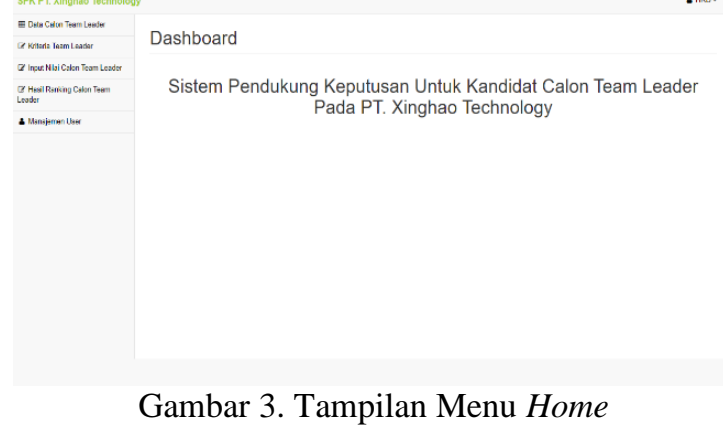

Setelah HRD melakukan proses login, akan muncul menu home seperti pada gambar di atas.

\section{Tampilan Data Calon Team Leader}

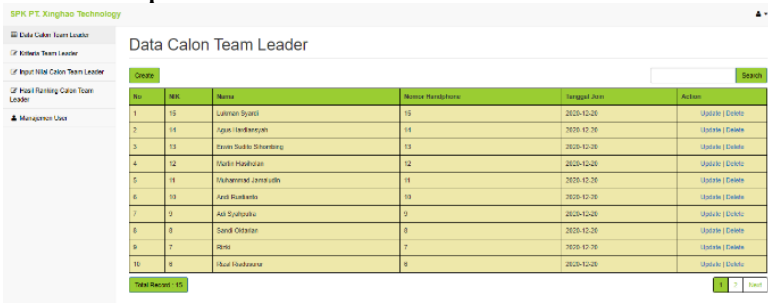

Gambar 4. Tampilan Data Calon Team Leader

Pada tampilan data alternatif menjelaskan bagaimana proses HRD memasukkan data calon team leader. 


\section{Tampilan Data Kriteria}

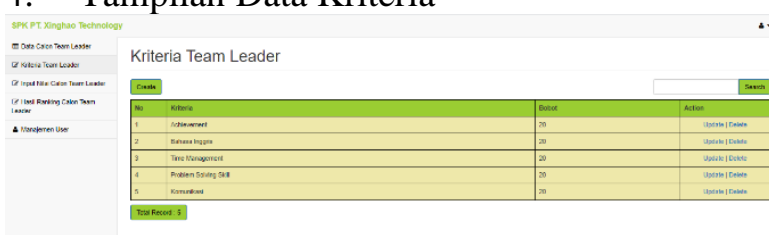

Gambar 5. Tampilan Data Kriteria

Pada tampilan data kriteria HRD dapat menambahkan kriteria dan bobot dari kriteria tersebut

\section{Tampilan Nilai Calon Team Leader}

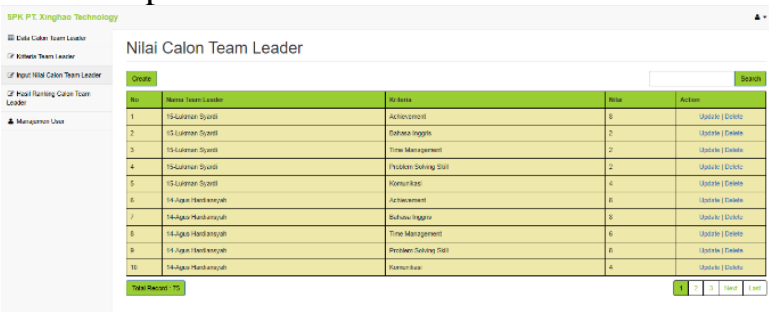

Gambar 6. Tampilan Nilai Calon Team Leader

Proses HRD memberikan penilaian kepada calon team leader

\section{Tampilan Hasil Analisa Calon Team Leader}

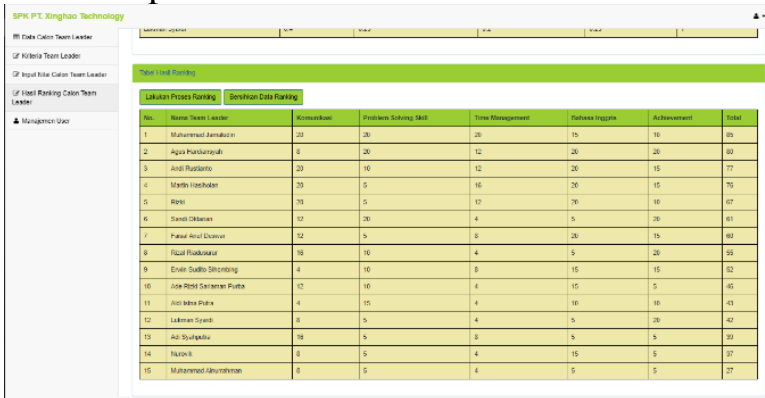

Gambar 7. Tampilan Hasil Analisa

Pada tampilan hasil analisa menjelaskan bagaimana HRD melakukan proses normalisasi dan pemeringkatan.

\section{Hasil Uji}

Pada hasil uji ini bertujuan agar peneliti mengetahui kelayakan aplikasi pada sistem pemilihan calon Team Leader. Pengujian ini menggunakan Blackbox testing yang berguna untuk mengecek fungsi button apakah bisa menampilkan menu-menu sesuai dengan yang diharapkan.

\section{- Black Box Login}

Mengecek setiap fungsi button login yang dilakuan hrd ketika masuk ke dalan sistem

Tabel 7. Pengujian Black Box Login

\begin{tabular}{|c|l|l|c|}
\hline Button & \multicolumn{1}{|c|}{ Skenario Penguji } & \multicolumn{1}{|c|}{ Hasil Uji yang Diharapkan } & Hasil \\
\hline \multirow{3}{*}{ Login } & Masukan username dan password tidak valid & Sistem menolak perintah login dari user & $\checkmark$ \\
\cline { 2 - 5 } & $\begin{array}{l}\text { Masukan salah satu username dan password } \\
\text { tidak valid }\end{array}$ & Sistem menolak perintah login dari user & $\checkmark$ \\
\cline { 2 - 5 } & Masukan username dan password valid & Sistem menerima perintah login dari user & $\checkmark$ \\
\hline
\end{tabular}

- Black Box Halaman Utama

Setelah berhasil melakukan proses login

selanjutnya akan menampilkan menu home dan menjelaskan setiap fungsi button halaman utama.

Tabel 8. Pengujian Black Box Halaman Utama

\begin{tabular}{|l|l|c|}
\hline \multicolumn{1}{|c|}{ Button } & \multicolumn{1}{c|}{ Hasil Uji yang Diharapkan } & Hasil \\
\hline Home & Berhasil masuk sehingga menampilan menu home & $\checkmark$ \\
\hline Data Calon Team Leader & Berhasil masuk sehingga menampilan menu data kandidat & $\checkmark$ \\
\hline Kriteria Team Leader & Berhasil masuk sehingga menampilan menu kriteria & $\checkmark$ \\
\hline Input Nilai Calon Team Leader & Berhasil masuk sehingga menampilan menu nilai & $\checkmark$ \\
\hline Hasil Ranking Calon Team Leader & Berhasil masuk sehingga menampilan menu ranking & $\checkmark$ \\
\hline
\end{tabular}

\section{E. Pengujian Akurasi}

Pada tahapan pengujian akurasi bertujuan untuk mendapatkan hasil dari perbandingan perhitungan manual yang dilakukan oleh HRD dengan perhitungan sistem yang lebih akurat dan efisien . 
Tabel 10. Tabel Pengujian Akurasi

\begin{tabular}{|c|c|c|c|c|c|c|c|c|c|c|c|}
\hline \multirow{2}{*}{ 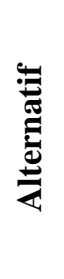 } & \multirow[b]{2}{*}{$\mathbf{C}_{1}$} & \multirow[b]{2}{*}{$\mathrm{C}_{2}$} & \multirow[b]{2}{*}{$\mathrm{C}_{3}$} & \multirow[b]{2}{*}{$\mathrm{C}_{4}$} & \multirow[b]{2}{*}{$\mathrm{C}_{5}$} & \multicolumn{4}{|c|}{ Perhitungan Manual } & \multicolumn{2}{|c|}{ Perhitungan Sistem } \\
\hline & & & & & & 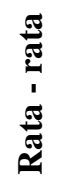 & 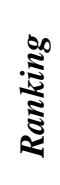 & 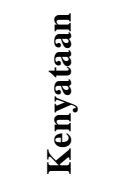 & 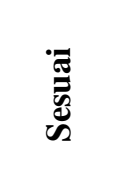 & $\frac{3}{\infty}$ & $\begin{array}{l}\ddot{W} \\
\overline{\tilde{D}} \\
\tilde{W}\end{array}$ \\
\hline $\mathrm{A}_{1}$ & 6 & 4 & 2 & 6 & 2 & 46 & 10 & 10 & 1 & 10 & 1 \\
\hline $\mathrm{A}_{2}$ & 2 & 6 & 2 & 4 & 4 & 43 & 11 & 11 & 1 & 11 & 1 \\
\hline $\mathrm{A}_{3}$ & 4 & 2 & 2 & 6 & 2 & 37 & 14 & 14 & 1 & 14 & 1 \\
\hline $\mathrm{A}_{4}$ & 4 & 2 & 2 & 2 & 2 & 27 & 15 & 15 & 1 & 15 & 1 \\
\hline $\mathrm{A}_{5}$ & 6 & 2 & 4 & 8 & 6 & 60 & 7 & 7 & 1 & 7 & 1 \\
\hline $\mathrm{A}_{6}$ & 8 & 4 & 2 & 2 & 8 & 55 & 8 & 8 & 1 & 8 & 1 \\
\hline $\mathrm{A}_{7}$ & 10 & 2 & 6 & 8 & 4 & 67 & 5 & 5 & 1 & 5 & 1 \\
\hline $\mathrm{A}_{8}$ & 6 & 8 & 2 & 2 & 8 & 61 & 6 & 6 & 1 & 6 & 1 \\
\hline $\mathrm{A}_{9}$ & 8 & 2 & 4 & 2 & 2 & 39 & 13 & 13 & 1 & 13 & 1 \\
\hline $\mathrm{A}_{10}$ & 10 & 4 & 6 & 8 & 6 & 77 & 3 & 1 & 0 & 3 & 1 \\
\hline$A_{11}$ & 10 & 8 & 10 & 6 & 4 & 85 & 1 & 2 & 0 & 1 & 1 \\
\hline$A_{12}$ & 10 & 2 & 8 & 8 & 6 & 76 & 4 & 4 & 1 & 4 & 1 \\
\hline$A_{13}$ & 2 & 4 & 4 & 6 & 6 & 52 & 9 & 9 & 1 & 9 & 1 \\
\hline $\mathrm{A}_{14}$ & 4 & 8 & 6 & 8 & 8 & 80 & 2 & 3 & 0 & 2 & 1 \\
\hline$A_{15}$ & 4 & 2 & 2 & 2 & 8 & 42 & 12 & 12 & 1 & 12 & 1 \\
\hline & & & & & & & & Total & 13 & Total & 15 \\
\hline & & & & & & & & Akurasi & $86,6 \%$ & Akurasi & $100 \%$ \\
\hline
\end{tabular}

Dari hasil pengujian yang sudah dilakukan dapat disimpulkan perbedaan tingkat akurasi dari perhitungan manual dengan perhitungan sistem. Setelah dilakukan pengujian, perhitungan manual memperoleh persentase nilai sebesar $86,6 \%$ sedangkan perhitungan sistem memperoleh persentase nilai sebesar 100\%. Dapat disimpulkan perhitungan sistem adalah pilihan yang tepat untuk digunakan dalam pemilihan calon Team Leader (Amelia \& Prianto, 2019).

\section{Kesimpulan}

Beberapa kesimpulan yang didapat pada sistem pendukung keputusan dalam pemilihan calon Team Leader menggunakan metode Simple Additive Weighting (SAW) adalah sebagai berikut:

1. Membantu HRD dalam memutuskan hasil yang tepat untuk pemilihan calon Team Leader yang singkron dalam bentuk pemeringkatan

2. Pada proses perhitungan sistem dalam pemilihan calon Team Ledaer menggunakan metode yang sangat akurat yaitu metode Simple Additive Weighting (SAW)

3. dengan hasil penelitian yang sudah diterapkan, dapat memudahkan HRD dalam memahami proses atau prosedur yang dilakukan dalam memilih kandidat calon Team Leader

\section{Referensi}

Agustina, M. (2019). Penentuan Team Leader, Supervisor Dan Facility Services Pada Perusahaan Jasa Berdasarkan Metode Simple Multi Attribute Rating Technique (Smart). Jurnal Ilmiah Matrik, 2l(1), 64-75. https://doi.org/10.33557/jurnalmatrik.v21i1.519

Amelia, S., \& Prianto, C. (2019). Uji Kinerja Metode Weighted Product Dan Simple Additive Weighting. Tehnik Informatika, 7(2), 1-10.

Cahyono, T. D., \& Hadikurniawati, W. (2019). Perancangan Model Waterfall Untuk Sistem Pendukung Keputusan Multi Attribute Dengan Metode Analytic Network Process. Dinamik, 23(1), https://doi.org/10.35315/dinamik.v23i1.7176

Gaol, L. C. L., \& Hasibuan, N. A. (2018). Sistem Pendukung Keputusan Pemilihan Team Leader Shift Terbaik Dengan Menggunakan Metode Aras Studi Kasus PT. Anugrah Busana Indah Lia. Informasi Dan Teknologi Ilmiah (INTI), 5(2), 101-106.

Kurniawan, A., \& Santika, R. R. (2020). Pemilihan Karyawan Terbaik Menggunakan Metode Simple Additive Weighting (SAW) Pada Perusahaan Investasi Emas. Jurnal Informatika Universitas Pamulang, 5(2), 167-174. https://doi.org/10.32493/informatika.v5i2.5265

Marpaung, N. (2018). Penerapan Metode Simple Additive Weighting Pada Sistem Pendukung Keputusan Untuk Menentukan Kenaikan Gaji 
Karyawan. Jurteksi, 4(2), 171-178. https://doi.org/10.33330/jurteksi.v4i2.58

Nurrahmi, H., \& Misbahuddin, B. (2019). Perbandingan Metode SAW (Simple Additive Weighting) Dan AHP (Analytic Hierarchy Process) Pada Sistem Pendukung Keputusan Pemilihan Karyawan Terbaik. Sainstech: Jurnal Penelitian Dan Pengkajian Sains Dan Teknologi, 29(1), 65-69. https://doi.org/10.37277/stch.v29i1.322

Putra, A. S., Aryanti, D. R., \& Hartati, I. (2018). Metode SAW (Simple Additive Weighting) Sebagai Sistem Pendukung Keputusan Guru Berprestasi ( Studi Kasus: SMK Global Surya). Prosiding Seminar Nasional Darmajaya, 1(1), 85-97. https://jurnal.darmajaya.ac.id/index.php/PSND/ar ticle/view/1233/763

Resti, N. C. (2017). Penerapan Metode Simple Additive
Weighting (SAW) Pada Sistem Pendukung Keputusan Pemilihan Lokasi Untuk Cabang Baru Toko Pakan UD. Indo Multi Fish. Intensif, 1(2), 102-107.

https://doi.org/10.29407/intensif.v1i2.839

Simatupang, J. (2018). Sistem Pendukung Keputusan Penentuan Karyawan Terbaik Menggunakan Metode SAW Studi Kasus Amik Mahaputra Riau. Intra-Tech, 2(1), 74-82. https://www.journal.amikmahaputra.ac.id/index.p $\mathrm{hp} / \mathrm{JIT} /$ article/view/27

Taufiq, R., \& Mustofa, I. S. (2017). Perancangan Sistem Pendukung Keputusan Kejurusan Menggunakan Metode Simple Additive Weighting (SAW) Di SMA Negri 15 Tangerang. Jurnal TI Atma Luhur, 4(1), 103-114. 